\section{SKUP3: a major step forward in sleep surgery research}

\author{
Eric J Kezirian
}

Positive airway pressure is recognised as the first-line treatment for moderate to severe obstructive sleep apnoea (OSA) in many countries because of its low risks and high efficacy. Unfortunately, between $30 \%$ and $40 \%$ of OSA patients cannot tolerate positive airway pressure ${ }^{12}$ and may consider other options, including surgery. The most common surgical treatment is isolated palate surgery (often one of the available uvulopalatopharyngoplasty techniques, with tonsillectomy for patients with palatine tonsils). Palate surgery has demonstrated improvements in measures of sleep-disordered breathing severity, such as the apnoea-hypopnea index (AHI), ${ }^{3}$ and has been associated with clinical benefits, such as improved quality of life, ${ }^{4}$ reduction in cardiovascular events ${ }^{5}$ and decreased mortality ${ }^{6}$ in cohort studies. However, the role of palate surgery (really, all surgery) remains controversial, because surgical outcomes can vary widely.

Browaldh and colleagues present the largest randomised trial comparing uvulopalatopharyngoplasty and tonsillectomy to observation alone for the treatment of moderate to severe OSA. With subjects who were primarily men, and had failed positive airway pressure and mandibular repositioning devices, the technique of stratified randomisation balanced the primary factors known to be associated with palate surgery outcomes (body mass index and Friedman Stage $\mathrm{I}$ vs $\left.\mathrm{II}^{7}\right)$. The study outcomes came from in-laboratory polysomnography an average of 7 months following surgery or observation alone. The study demonstrated statistically significant and clinically meaningful improvements in OSA severity (both for the AHI and oxygen desaturation index) in the uvulopalatopharyngoplasty/tonsillectomy group, but none in the observation group. It is important that a meaningful number of patients in the former group continued to demonstrate mild to moderate OSA (discussed below). Figure 3 from the publication highlights the consistent pattern of improvement in AHI for intervention group subjects without changes for the

Correspondence to Dr Eric J Kezirian, Department of Otolaryngology — Head and Neck Surgery, University of California, San Francisco, CA 94115, USA; ekezirian@ohns.ucsf.edu control group. Importantly, there were no changes in body mass index in either group.

OSA surgery, compared with other surgical fields, has a relatively large number of randomised trials that either compare surgical interventions to placebo, two surgical treatments against each other, or surgical versus non-surgical treatment. However, Browaldh and colleagues present only the second published study (and by far the larger study) comparing surgery with observation; the first ${ }^{8}$ was limited by small sample size. Randomised trials comparing surgery (any type) with observation are plagued with a number of problems, including ethical concerns (one possible reason the Browaldh study was initially not approved by the Swedish Regional Ethics Committee), to feasibility (enrollment is notoriously difficult). The investigators should be applauded for the successful completion of such a large study.

The study is important for its own findings and its broader implications for OSA surgery research. This study showed that uvulopalatopharyngoplasty with tonsillectomy achieves substantial improvements in OSA severity, whereas observation alone does not. These results are similar to those reported in the investigators' previous retrospective cohort study of uvulopalatopharyngoplasty/tonsillectomy ${ }^{9}$ and those reported by others. ${ }^{7}$ One of the major criticisms of the OSA surgery literature has been the paucity of randomised trials comparing surgery to observation; this study suggests that large interventional trials or cohort studies may be sufficient, at least for evaluation of polysomnography outcomes, because OSA does not spontaneously regress with observation alone.

Critics of OSA surgery will point to the fact that surgery did not normalise OSA in all surgical group subjects, ${ }^{10}$ which has been shown in previous studies also. ${ }^{11} 12$ This criticism overlooks a number of important factors: these subjects had failed alternatives, so the reasonable comparison is to observation alone rather than these other, non-viable options; up to $75 \%$ of satisfied users of continuous positive airway pressure therapy will have evidence of OSA (AHI >5 events/h), even during treatment at their titrated pressure setting $^{13}$; patients often refuse more invasive surgical options like maxillomandibular advancement ${ }^{14}$; and the substantial improvements in OSA severity are likely clinically meaningful for many patients even if AHI does not normalise.

The study has a number of strengths not limited to the methodological rigour. The inclusion of eight surgeons (to enhance generalisability), a standardised surgical technique and blinded polysomnogram readings are all features that could be adopted more widely by other researchers. However, there are some limitations that the authors correctly identify. One is the lack of other objective and any subjective outcomes. Measures of OSA severity from polysomnography are important OSA treatment outcomes, yet they are intermediate outcomes that may or may not correlate with clinical endpoints: subjective measures like sleepiness, quality of life and objective assessments of cardiovascular disease. There are conflicting studies suggesting that improvements in these clinical metrics are ${ }^{15}$ or are not ${ }^{16}$ associated with AHI changes with treatment.

This study has contributed substantially to OSA surgery and OSA surgery research. Future investigations can build on this work through the incorporation of additional outcome measures, examination of other surgical interventions (including hypopharyngeal or retrolingual procedures that may improve outcomes over palate surgery alone), ${ }^{11}{ }^{12}$ and evaluation of factors associated with surgical outcomes. $^{17}$

Competing interests None to declare. The author has the following financial disclosures: Apnex Medical (Medical Advisory Board, Consultant); ArthroCare (Consultant); Medtronic (Consultant); Pavad Medical (Consultant); ReVENT Medical (Medical Advisory Board); Split Rock Scientific (Medical Advisory Board).

Provenance and peer review Commissioned; externally peer reviewed.

To cite Kezirian EJ. Thorax 2013;68:801-802.

Published Online First 28 May 2013

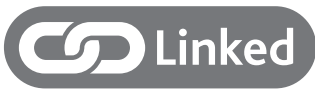

- http://dx.doi.org/10.1136/thoraxjnl-2012-202610

Thorax 2013;68:801-802.

doi:10.1136/thoraxjnl-2013-203681

\section{REFERENCES}

1 Kribbs NB, Pack Al, Kline LR, et al. Objective measurement of patterns of nasal CPAP use by patients with obstructive sleep apnea. Am Rev Respir Dis 1993;147:887-95.

2 Weaver TE, Grunstein RR. Adherence to continuous positive airway pressure therapy: the challenge to effective treatment. Proc Am Thorac Soc 2008;5:173-8. 
3 Caples SM, Rowley JA, Prinsell JR, et al. Surgical modifications of the upper airway for obstructive sleep apnea in adults: a systematic review and meta-analysis. Sleep 2010;33:1396-407.

4 Weaver EM, Woodson BT, Yueh B, et al. Studying Life Effects \& Effectiveness of Palatopharyngoplasty (SLEEP) study: subjective outcomes of isolated uvulopalatopharyngoplasty. Otolaryngol Head Neck Surg 2011;144:623-31.

5 Peker Y, Hedner J, Norum J, et al. Increased incidence of cardiovascular disease in middle-aged men with obstructive sleep apnea: a 7-year follow-up. Am J Respir Crit Care Med 2002;166:159-65.

6 Marti S, Sampol G, Munoz X, et al. Mortality in severe sleep apnoea/hypopnoea syndrome patients: impact of treatment. Eur Respir 1 2002;20:1511-8.

7 Friedman M, Ibrahim H, Bass L. Clinical staging for sleep-disordered breathing. Otolaryngol Head Neck Surg 2002;127:13-21.
8 Lojander J, Maasilta $\mathrm{P}$, Partinen $\mathrm{M}$, et al. Nasal-CPAP, surgery, and conservative management for treatment of obstructive sleep apnea syndrome. A randomized study. Chest 1996;110:114-19.

9 Lundkvist K, Januszkiewicz A, Friberg D. Uvulopalatopharyngoplasty in 158 OSAS patients failing non-surgical treatment. Acta Otolaryngol 2009;129:1280-6.

10 Elshaug AG, Moss JR, Southcott AM, et al. Redefining success in airway surgery for obstructive sleep apnea: a meta analysis and synthesis of the evidence. Sleep 2007;30:461-7.

11 Kezirian EJ, Goldberg AN. Hypopharyngeal surgery in obstructive sleep apnea: an evidence-based medicine review. Arch Otolaryngol Head Neck Surg 2006;132:1-8.

12 Sher AE, Schechtman KB, Piccirillo JF. The efficacy of surgical modifications of the upper airway in adults with obstructive sleep apnea syndrome. Sleep 1996;19:156-77.
13 Pittman SD, Pillar G, Berry RB, et al. Follow-up assessment of CPAP efficacy in patients with obstructive sleep apnea using an ambulatory device based on peripheral arterial tonometry. Sleep Breath 2006:10:123-31.

14 Kezirian EJ, Hussey HM, Brietzke SE, et al. Hypopharyngeal surgery in obstructive sleep apnea: practice patterns, perceptions, and attitudes. Otolaryngol Head Neck Surg 2012;147:964-71.

15 Kezirian EJ, Malhotra A, Goldberg AN, et al. Changes in obstructive sleep apnea severity, biomarkers, and quality of life after multilevel surgery. Laryngoscope 2010;120:1481-8.

16 Weaver EM, Woodson BT, Steward DL. Polysomnography indexes are discordant with quality of life, symptoms, and reaction times in sleep apnea patients. Otolaryngol Head Neck Surg 2005;132:255-62.

17 Kezirian EJ, Weaver EM, Criswell MA, et al. Reporting results of obstructive sleep apnea syndrome surgery trials. Otolaryngol Head Neck Surg 2011;144:496-9. 